\title{
The Musical Language of Zeqirja Ballata in His Piano Work Fantasia Rustica
}

\author{
Indira Çipa \\ University of Prishtina, Pristina, Kosovo \\ Email: indiracipa@gmail.com
}

How to cite this paper: Çipa, I. (2018) The Musical Language of Zeqirja Ballata in His Piano Work Fantasia Rustica. Advances in Anthropology, 8, 302-315. https://doi.org/10.4236/aa.2018.84013

Received: October 1, 2018

Accepted: November 16, 2018

Published: November 19, 2018

Copyright $\odot 2018$ by author and Scientific Research Publishing Inc. This work is licensed under the Creative Commons Attribution-NonCommercial International License (CC BY-NC 4.0). http://creativecommons.org/licenses/by-nc/4.0/

\begin{abstract}
Zeqirja Ballata (1943), a Kosovar composer, is in step with the works of his time, more precisely belonging to the postmodernist period. Throughout his musical opus, he showed consistency to the contemporary stylistic elements of the second half of the twentieth century. Among the 157 musical works by the Kosovar composer Zeqirja Ballata, this paper brings the results of the analysis of the musical language used in Fantasia rustica (for the left hand). The work in question is atonal, with dominant dissonance followed by short consonant bursts. Employing a qualitative research method, or analysis, the work was analysed including the following musical parameters: general and historical data of the piece, structure, linear expression, consonant structures, rhythm and its components, dynamics and synthesis of musical parameters in the process of concretization. The paper also contains notation tables and examples illustrating concretization moments.
\end{abstract}

\section{Keywords}

Work, Pianistic, Linearity, Consonance, Dynamics

\section{Introduction}

This paper provides a part of the observations and analyses included in the study of Veprat Pianistike të Zeqirja Ballatës promovuese të stilit bashkëkohor (Paino Pieces of Zeqirja Ballata-promoters of the contemporaneous style). Ballata is a contemporary Kosovar composer, who created 157 musical pieces from which 14 are piano pieces. If we also include his three lost piano pieces the category of his piano pieces amounts to a total of 17. His musical language is made of contemporaneous novelties of Western European music. Following European trend of novelties in music, he used many elements and techniques of postmodern music (Križnar, 2004). In the analysis of this work, the suggestion of D. Michael 
that one should not analyze a contemporaneous work in terms of style but rather in terms of the language used has also been taken into consideration (Michel, 1983). Through a general observation of Ballata's musical language it can easily be said that his musical language is completely atonal. He incorporates elements of integral and incomplete serialism, discrete elements of punctualism, accentuated dissonance, extreme dynamic contrasts, acoustic products, and symbols from contemporaneous notation, clusters as well as many other elements (Berisha, 1997). These elements of his musical language indicate that Ballata was a consequent follower of contemporaneous trends of the second half of the $20^{\text {th }}$ century. His linear expression is made of nucleutic and motivic structures. Whereas, his vertical structuring is mostly comprised of the technique of overlapping dissonant intervals.

The characteristics of Fantasia rustica, will be illuminated through the results of the analysis presented in this paper. From a total of 14 piano pieces of Ballata, Fantasia rustica (1964) along with Echi delle Montagne Maledette (1963) comprise the two pieces for the left hand and his pre-study composing endeavors. Highlighted elements of postmodernism which constitute the expressive language in Fantasia rustica remain present, are developed, and strengthened throughout his whole musical career, and as such are included in all the categories he composes.

The following analysis is based mainly on the theory and the analytical format of T. Mančev, who focuses the analytical observation of a musical work in the MOVING role of musical parameters and other elements (Mančev, 2001). The mentioned theory coincides with the philosophical idea of Focht treated as tectonics in music, namely the importance of tension is seen in the conjuncture of the horizontal movement with the vertical organization (Foght, 1980).

\section{General Data and History of the Work}

After Echi delle Montagne maledette (1963), which belongs to his pre-university years, Ballata composes the Fantasia rustica for the left hand (1964). This piece has been published in the diptych titled Dve skladbi za klavir (Ballata, 1970) by the Society of Slovene Composers (ED. DSS. Št.379. Ljubljana).The work is organized into 63 bars with a high variability metrics from $5 / 4,4 / 4,3 / 4$ to $2 / 4$. Its Allegro non troppo tempo with a cadence cca $\downarrow=88$ changes to cantando lamentoso meno mosso during the course, and again restores to tempo primo. As we explore the subjective peculiarities of the work, the following passage from the unstructured interview with the author is worthy of attention: In this work prevails a folkloric environment where I have taken care to get rid of the original clarity. Regarding the organization and distribution of the material in hands, I have given priority to the left hand, which I consider to be a very bold decision for the time when I composed it. Fantasia rustica is the second in turn composed for the left hand. I have dedicated this work to the Slovenian pianist Tatjana Buçar, as a sign of gratitude for her demonstrative interpretation, for the interest 
and encouragement that she had given me during this time. Buçar then performed it very often at concerts. This work represents the continuity of the spirit that I brought long ago in the work "Au Village" (from the interview conducted with Z. Ballata in May2016).

\section{The Structure}

Among the main objectives of analysing the structure of a musical work is its division into parts which constitute that structure, paying attention to the content of those parts, as well as to their relationship with each other, and to the work as a whole (Dušan \& Vlastimir, 1986). Fantasia rustica is a single movement work constructed with slightly independent but at the same time similar sections. The first section extends from B-1 to B-17. The last four bars have a cadence role (B-14-17). The first sentence of this section is in B-1-3. From B-4 to B-8 is the other sentence which is independent from the first sentence. From B-9 to half of B-12 is the third sentence concluding in the melodic state $\mathrm{Fa} \#$. The following is the closure of the section's thought with a cadence segment and extending from B-14-17, where the first section closes. The second section is short. It extends from B-18-24 and is independent of the first section. The third section begins in B-25 and extends up to B-48, where we encounter elements from $a$ and al material of the first section. The segment from B-49-63 has the role of a repetition that contains elements from all the previous sections where B-49 starts as the entry of the section that is in the bass, while the sequel is with quotations of the parts of the preliminary sections (See Table 1).

\section{Linear Expression}

Ornamentalism in Ballata's piano works is a modestly used tool. The presence of ornaments in this work is presented as a dramaturgical tool deriving from the necessity of describing the thematic content implied by the title of the work. The interval movement of the ornament, which precedes the first movement, defines and describes the thematic semantic object in a particular way. The linear quint-quart movement, as one of the distinguishing features of the composer, especially in vertical structures, is followed by sequences of seconds (See Figure 1).

The ornament presented in Figure 1 as well as the frequent appearance of its fragments during the entire flow of the work, make the ornamentation in this work to be considered as a major element of the aesthetic expression of the

Table 1. Structure.

\begin{tabular}{cccc}
\hline No. & Structural subject & Bar & Microstructure \\
\hline 1 & Section I & $1-17 \quad$ a:3 + a1:5 + a2:4 + cadence and cadence segment: $1+4$ \\
2 & Section II & $18-24$ & $2+2+3$ \\
3 & Section III & $25-48$ With elements of $a$ and al of the first section \\
4 & Section IV & $49-63$ a type of repetition with elements from the previous sections \\
\hline
\end{tabular}




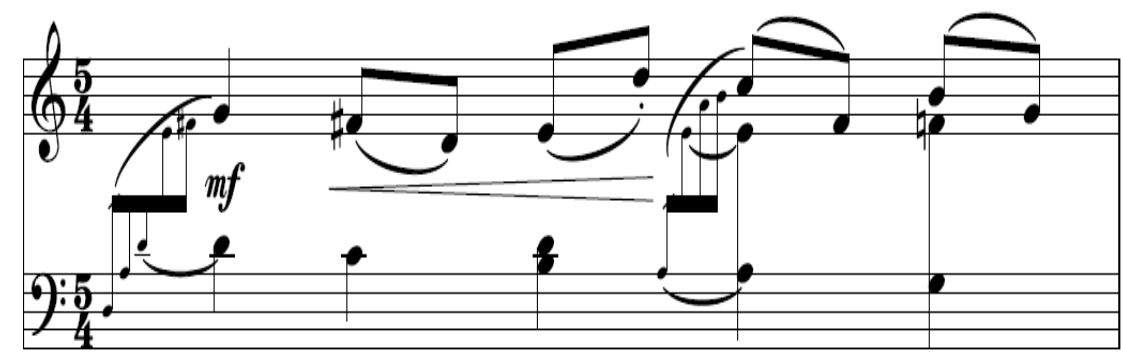

Source: Dve skladbi za klavir/Fantasia rustica.1970. ED.DSS ŠT. 379. Pg. 6-11.

Figure 1. (B-1).

melody, which brings and reinforces the rustic spirit as intended in the title. The structure of the melodic movement, the type of narrative as well as the lack of tonal gravitation in the melodic movement, indicate its athematic nature. It relies on a small melodic note Sol, Fa \#, Re. It's melo-rhythmic and intonation variations during the work, preserve the note shortness, the interval ratio of the movement with the possibilities that bring about the possible overtures of the melodic material. The presence of the introductory ornamentation, i.e. its fragments, is also preserved. Ornaments of different shapes appear quite often and are indicative that its appearance in the introductory segment is one of the main means of aesthetic expression of the melody. They are found in the bars 1, 5, 12, $33,35,36,37,38,40,50$. Thus ornaments, expressing one of the characteristics of rustic aesthetics, become part of the elaboration of the musical composition and of the content that brings the meaning of title. The search for melodic and thematic integrity is, at the first bar, impeded by the imposition of the extended intervals, leaving the impression that the acoustic effect and interaction of subjects in the verticals determine the character of the linearity (melody). For illustration we are showing the fragment with the densest presence of ornaments (See Figure 2).

Bars 3 and 4, in a close placement of the soprano with the alto and with a thematic acting role of both tones, bring some kind of melodic narrative movement. The clearest individualization of melodic code occurs in B-4 and develops up to B-12. A melody with developing opportunities of movement enters in space within this segment. This is clearly distinguished from the chord accompaniment and is expressed by repetition of its own fragments with developmental principles, with the interval and chord relationships forerun in B-1-3. Whereas in the rhythmic aspect, it is expressed in thematically personalized figures, carrying the necessary flow energies ( 1 eighth, 2 semiquavers). The following one is melodically overturned in the opposite direction (See Figure 3 ).

A syncopation in B-7 foreshadows the half-ending of the phrase in the B-8 with the use of sextuplet and triplet in bass, below a quartet of soprano-alto. This is continuously repeated twice by creating the segment of the effort to conclude the development of melodic material, which finally takes place in B-13, this time with new tools of greater execution capability: overlapping eighths, chord with dissonant structure and again eighth. The last B-13 movement 

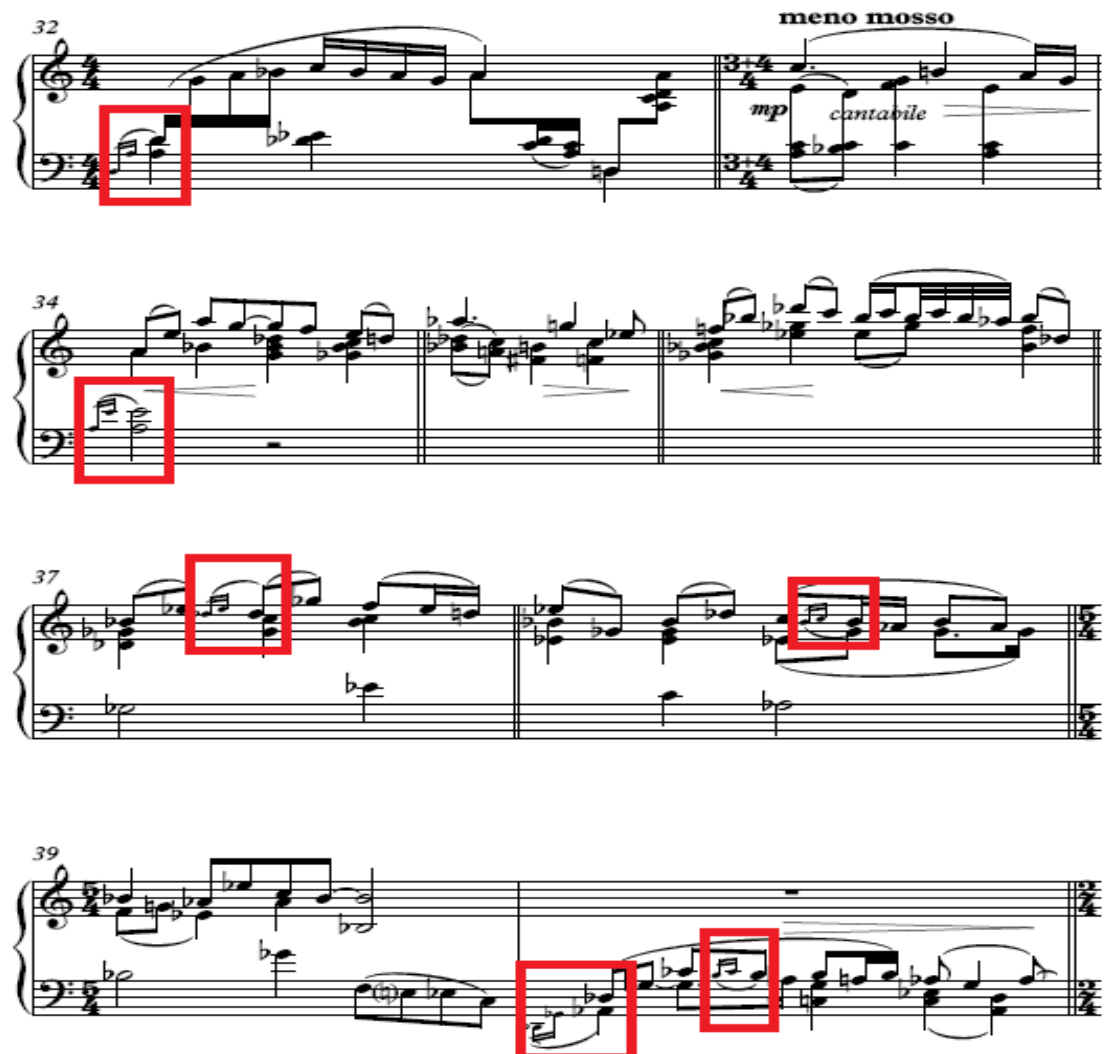

Source: Dve skladbi za klavir/Fantasia rustica. 1970. ED.DSS ŠT. 379. Pg. 6-11.

Figure 2. (B-33-40).

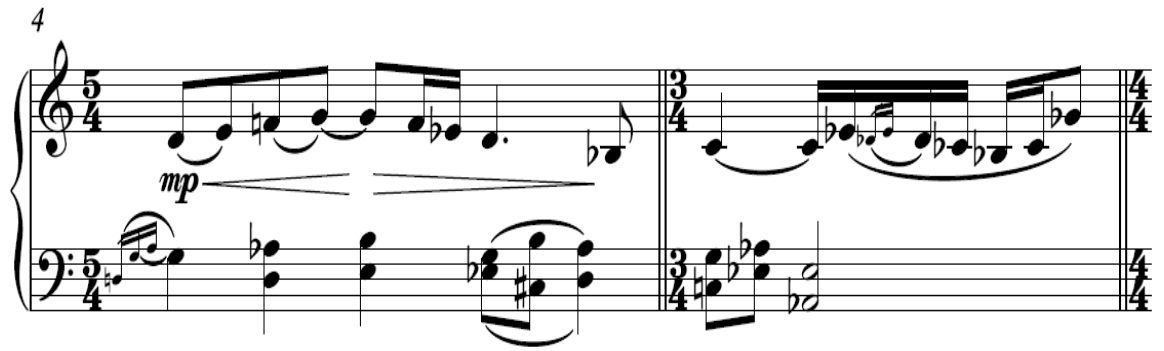

Source: Dve skladbi za klavir/Fantasia rustica. 1970. ED.DSS ŠT. 379. Pg. 6-11.

Figure 3. (B-4-5).

marks the beginning of the cadence segment, and in terms of content, has nothing to do with the previous flow (See Figure 4).

The melody of this work is sometimes dependent on the acoustic effect of the vertical and sometimes expresses complete independence. The motivic material, or the characteristic melodic fragments, is the subject with which the composer alternates during the further elaboration of the work using techniques such as: retention of the rhythmic figure and melody striping from the moving identity, recreation of rhythmic figures through legacy of source melodic values, transfer of melodic segments from one tone to another, etc. (See Figure 5).

The melodic fragments from the initial section are noticeable throughout the interpretation of the work, of course, except in the cadence segments and small 


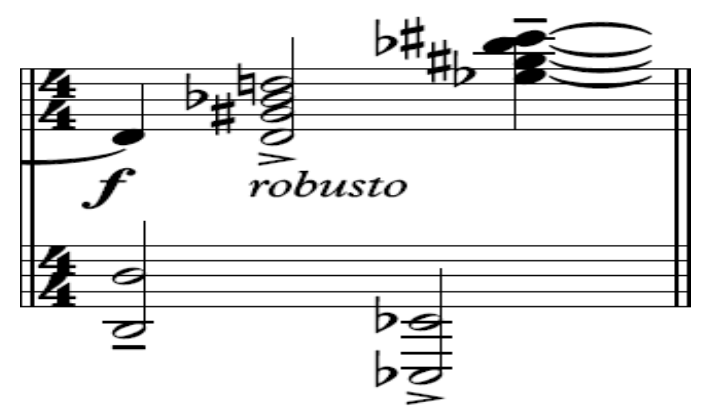

Source: Dve skladbi za klavir/Fantasia rustica. 1970. ED.DSS ŠT. 379. Pg. 6-11.

Figure 4. (B-13).

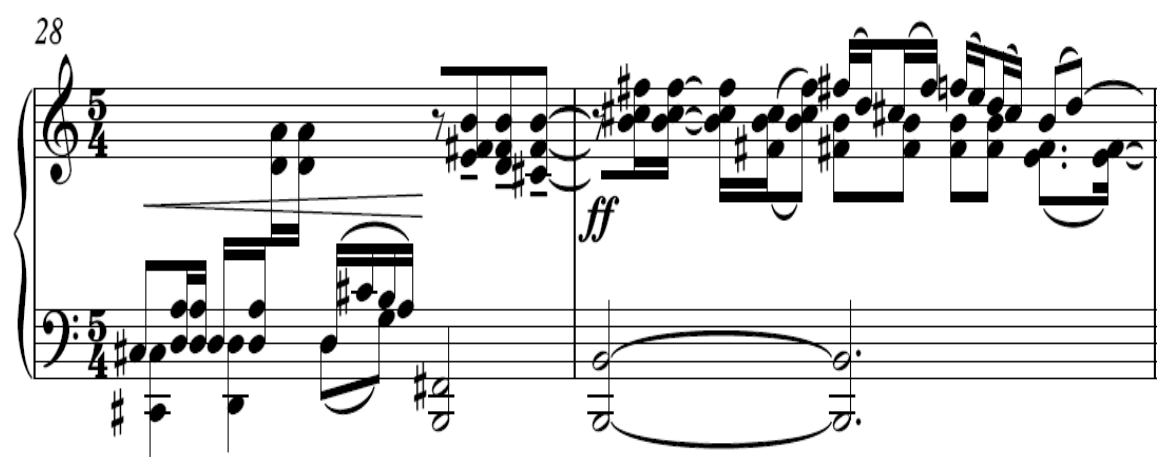

Source: Dve skladbi za klavir/Fantasia rustica. 1970. ED.DSS ŠT. 379. Pg. 6-11.

Figure 5. (B-28-29).

bridges. The melody has a pronounced relief that is expressed by the techniques of switching from the register to register, from tone to tone, from hand to hand, changing the direction of development and inversing the rhythmic grouping.

\section{The Consonant Structures}

Fantasia rustica begins with an ornamental arpeggio, within which the third sound is held, in order to create the intervals aligned in the linear course (2-3-4). The stride of the arpeggio with a lack of tercet gives the sense of indefinability of the homonymous tonalities (in this case Re-minor-Re-major), a characteristic found also in other works of the composer (See Figure 6).

The linear quint-quart movement and its overlapping here is also a means of expressing consonant structures. In the second unit we have a transition of quartet into second. Repetition of the arpeggio once again brings the same play on the vertical, which in the end results in overlapped quint-sextet. This creates the temporal illusion of La-minor, which, through following sextet, goes to a dominant septachord of Do-major. The overlapping quartets in B-2 and then the soprano movement in quartets over the static bass and alto bring the movement of the vertical structure by creating new consonant relationships in relation to the bass and alto (7-10-9) (See Figure 7).

Intertwining the consonants with the logic of interval overlapping as one of the means of expression in vertical structuring, during musical interpretation, 


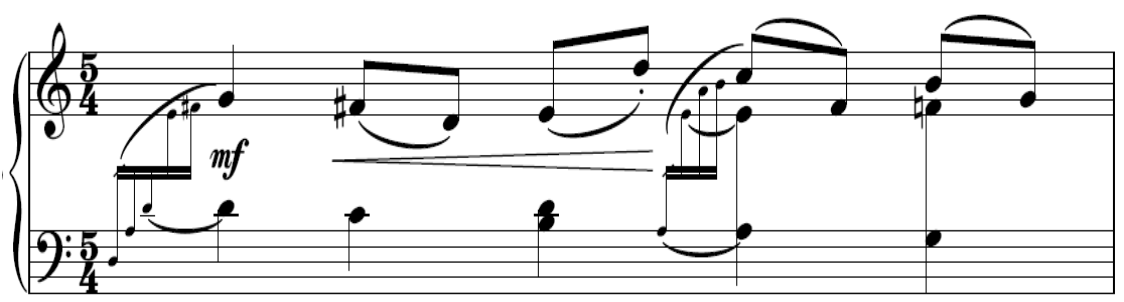

Source: Dve skladbi za klavir/Fantasia rustica. 1970. ED.DSS ŠT. 379. Pg. 6-11.

Figure 6. (B-1).
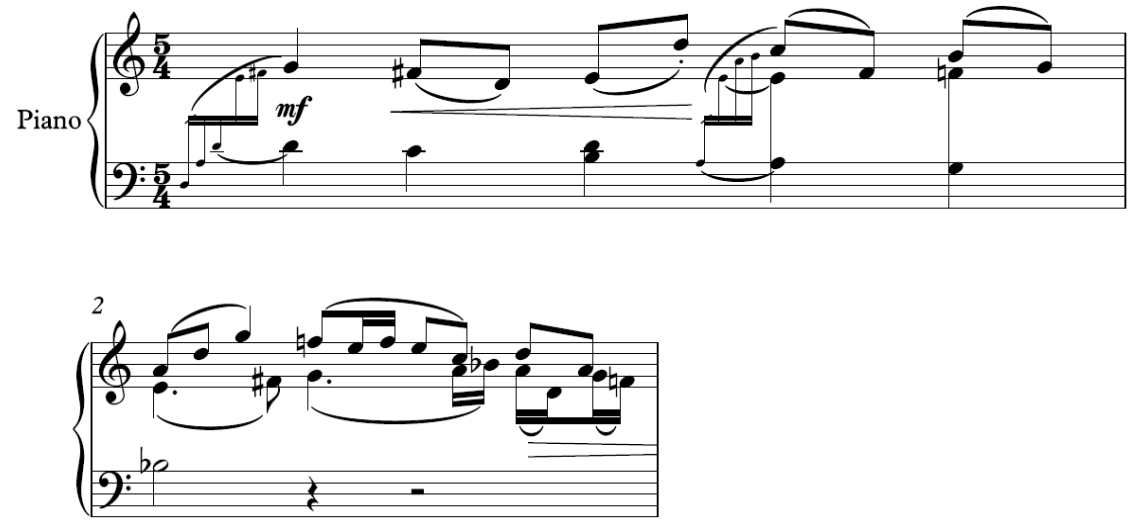

Source: Dve skladbi za klavir/Fantasia rustica. 1970. ED.DSS ŠT. 379. Pg. 6-11.

Figure 7. (B-1-2).

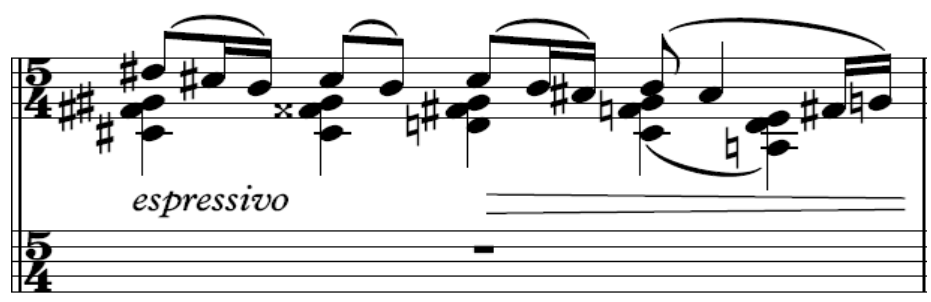

Source: Dve skladbi za klavir/Fantasia rustica. 1970. ED.DSS ŠT. 379. Pg. 6-11.

Figure 8. (B-7).

brings unlimited combinations of overlapping intervals, ranging from minor second to the major decimal. Thus, the dissonances substitute each other sometimes with gradual movement, sometimes with overlaps and transpositions from one to the other side of consonant vertical. In certain segments, a certain tone appears spreading to the movement of other tones, which relieve the consonant structures, whether chord or interval. Segments that have clear melodic movements are accompanied with tridimensional chords and with the effect of the seconds created by the overlapping quart-quants or quart-seconds. This logic of overlapping intervals prevails throughout the whole work (See Figure 8).

\section{Rhythm and Its Components}

1) Meter-The change of the metric bar in Fantasia rustica is even more frequent than in the Echi delle Montagne Maledette. In its string of 64 bars 38 
changes occur, including metric bar couplets such as $(3 / 4+4 / 4) \times 6(\mathrm{~B}-14),(3 / 4$ $+4 / 4) \times 3(\mathrm{~B}-34)$ and $(4 / 4+3 / 4) \times 2(\mathrm{~B}-59)$. Let's note that the irregular bar $5 / 4$ is prevalent, while $3+4$ or $4+3$ couplets bring a rhythmic Albanian folk spirit to the musical interpretation, creating a sense of a 7/4 (See Table 2).

2) Metric dynamics - In contrast to other works, where metric dynamics, or accents, is very active either as aesthetic, stylistic or metric means, in Fantasia rustica, the composer deviates from his own characteristic tendency. The use of accents is modest; there are only ten. It is peculiar that the tenuto's are used in this work. Because the analytic form does not envisage specific treatment of articulations, besides the metric dynamics, there will be presented also the overview of the tenutos and the comments on them because of the aesthetic role they play in the work. There are no more than six signs that accompany the special narrative and dramatic moments (See Table 3 ).

3) Rhythm-In this work, rhythm is one of the important conveyors of the intended dramaturgy. In the broad sense of the word, the constant change of the metric bar exercises a significant influence on the general rhythmical effect. Specifically, couplets $3+4 / 4$ give the work the rustic element, thus placing it in a national Albanian character. Ornaments as a rhythmic phenomenon bring their unique individuality. In most cases, presented as semiquaver and eighth values, they also impact other parameters such as: the character of the melody, the timbre

Table 2. Overview of metre changes.

\begin{tabular}{|c|c|c|c|c|c|c|c|c|c|}
\hline 1 & Bar & 1 & 3 & 4 & 5 & 6 & 7 & 8 & 9 \\
\hline 2 & The amount of metric units & 5 & 4 & 5 & 3 & 4 & 5 & 2 & 5 \\
\hline 3 & The value of metric units & 4 & 4 & 4 & 4 & 4 & 4 & 4 & 4 \\
\hline 1 & Bar & 10 & 11 & 13 & 14 & 26 & 27 & 28 & 29 \\
\hline 2 & The amount of metric units & 4 & 5 & 4 & $3+4 \times 6$ & 5 & 3 & 4 & 5 \\
\hline 3 & The value of metric units & 4 & 4 & 4 & 4 & 4 & 4 & 4 & 4 \\
\hline 1 & Bar & 31 & 32 & 33 & 34 & 40 & 42 & 43 & 45 \\
\hline 2 & The amount of metric units & 4 & 3 & 4 & $3+4 \times 3$ & 5 & 2 & 5 & 4 \\
\hline 3 & The value of metric units & 4 & 4 & 4 & 4 & 4 & 4 & 4 & 4 \\
\hline 1 & Bar (position) & 46 & 48 & 49 & 53 & 54 & 56 & 58 & 59 \\
\hline 2 & The amount of metric units & 3 & 4 & 5 & 4 & 3 & 4 & 3 & $4+3 \times 2$ \\
\hline \multirow[t]{3}{*}{3} & The value of metric units & 4 & 4 & 4 & 4 & 4 & 4 & 4 & 4 \\
\hline & Change frequency & 38 & & & & & & & \\
\hline & Frequency of metric unit type & 1 & & & & & & & \\
\hline
\end{tabular}

Table 3. Metric dynamics.

\begin{tabular}{ccccccccccc}
\hline Bar & 12 & 13 & 14 & 15 & 16 & 17 & 28 & 29 & 44 & Freq. \\
\hline No. of accents & 2 & 2 & 1 & 1 & 2 & 1 & 0 & 0 & 1 & 10 \\
No. of tenutos & 0 & 2 & 0 & 0 & 0 & 0 & 1 & 3 & 0 & 6 \\
\hline
\end{tabular}


and the general character. The melodic material, is mostly realized with eighths and semiquaver organized as one eighth and two semiquavers and their inversion (See Figure 9).

Often, the composer uses note punctuation and syncopation, as: a) energizing means for further string development (See Figure 10), b) separating means from subsequent repetition (See Figure 11), c) an opportunity for rhythmic variation of melodic elements (See Figure 12).
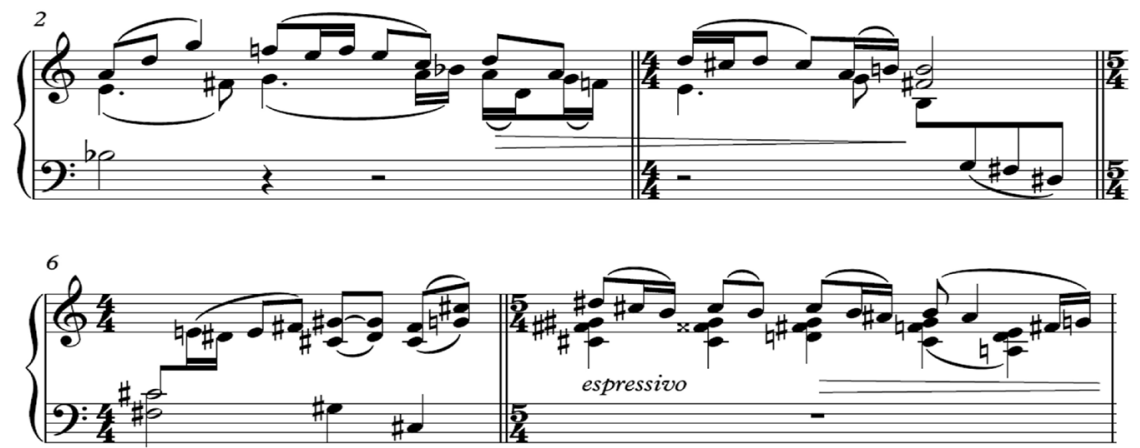

Source: Dve skladbi za klavir/Fantasia rustica. 1970. ED.DSS ŠT. 379. Pg. 6-11.

Figure 9. (B-2-3-6-7).

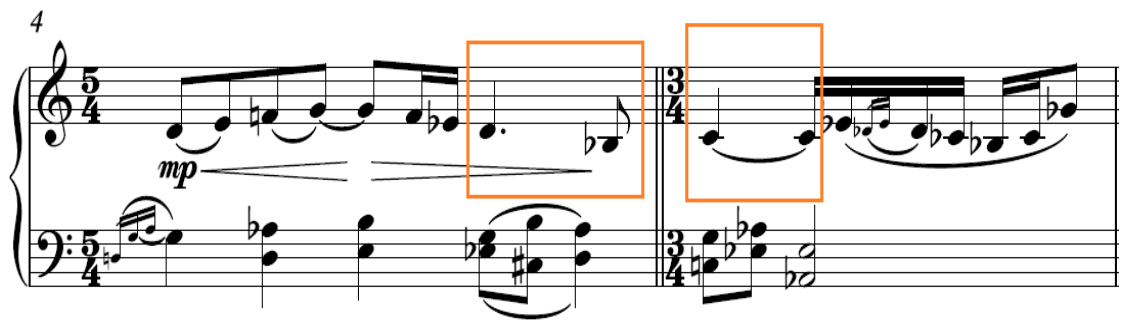

Source: Dve skladbi za klavir/Fantasia rustica. 1970. ED.DSS ŠT. 379. Pg. 6-11.

Figure 10. (B-4-5).
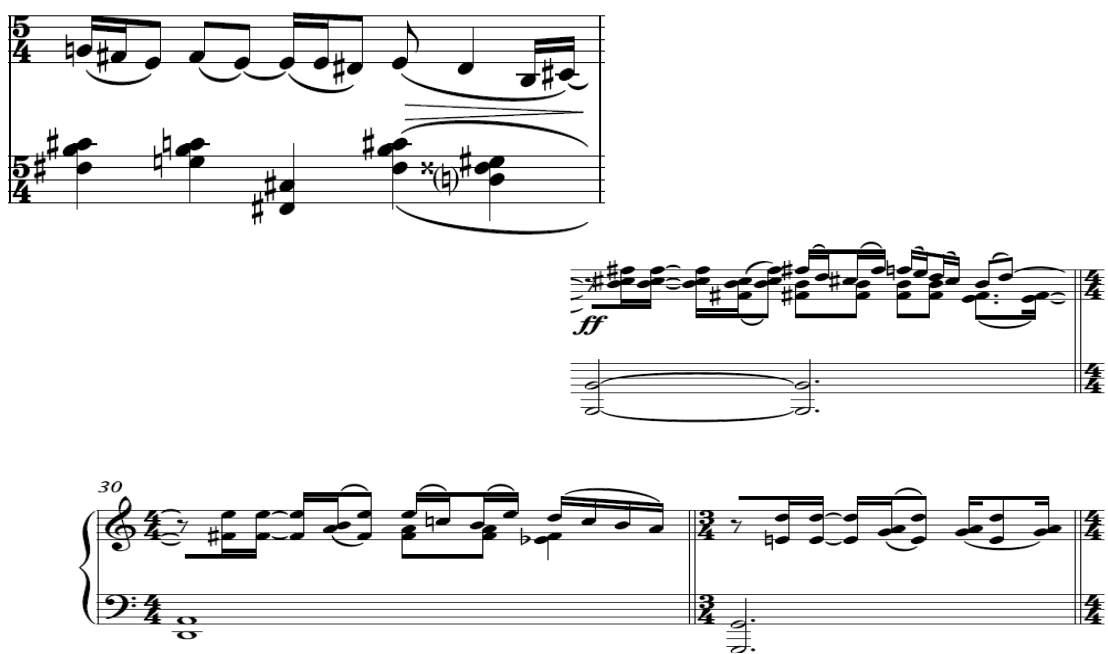

Source: Dve skladbi za klavir/Fantasia rustica. 1970. ED.DSS ŠT. 379. Pg. 6-11.

Figure 11. (B-9-29-30-31). 

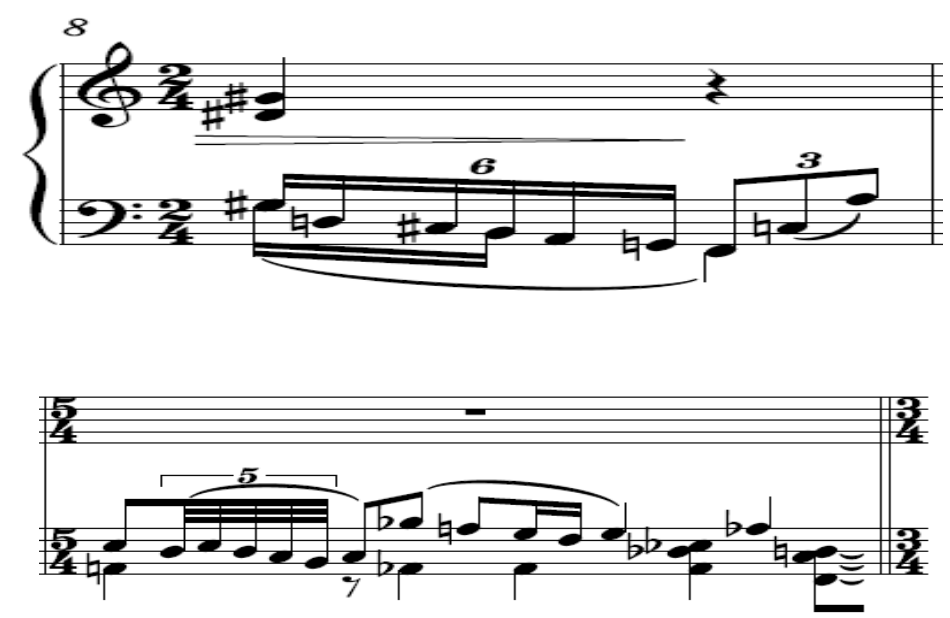

Source: Dve skladbi za klavir/Fantasia rustica. 1970. ED.DSS ŠT. 379. Pg. 6-11.

Figure 12. (B-8, 25).

Irregular rhythmic figures appear in function of the structural syntactical tool. In certain bars, they accomplish the division of repeated fragments.

A single use of a semiquaver figure, found in B-37, has rhythmic flow processing character. No polyrhythms or polymetres are found. The opening and cadence segments of the structural zones are realized with 4ths, halves, and so on.

4) Tempo, agogics and character notes-The general character and the envisaged Allegro non troppo tempo in Fantasia rustica is relatively distant from the general character of Andante con variacioni i Echi delle Montagne Maledette. Meanwhile in the metronomic value, the two works have a significant similarity $\mathcal{L}=80$ with 88 . In a string of a total of 64 bars, in B-7 there is espressivo, which rapidly exits the string to be replaced by a robusto that accompanies and characterizes more accurately the dynamics of $f$ in B-13. Cantando lamentoso enters the string at B-18. Dynamic development, which starts at B-25, will last until B-33. With the simultaneous appearance meno mosso and cantabile, the B-34 brings a radical change, thus affecting both tempo and character. Tempo I-mo. is transformed toB-50 and, with the exception of the marcato in $\mathrm{B}-5$ that is considered as a characteristic of the dynamics $f$, there is no other note of the respective categories. It should be mentioned that in this work, except of meno mosso, no other agogic note is used. Changes in tempo, agogics and character, in a particular way, structure the work as follows: allegro non troppo $M 1$-17, cantando lamenoso B-18-33, meno mosso B-34-49, tempo I-mo B-50-64 (See Table 4).

\section{Dynamics}

In a string of 63 bars, the composer has used a total of 51 dynamic notes. The dynamic frame of the first fragment is marked with dynamics $f$, wherewith is passed to decrescendo to $m p(\mathrm{~B}-4)$. An additional tenderness is suggested by expressions of character articulation in B-7 (espressivo)). The segment B-18-24 is permeated with $m p$ with small crecsendo and decrescendo following the character 
Table 4. Changes in tempo, agogics, and character.

\begin{tabular}{cccccc}
\hline No & Change & Bar & No. & Change & Bar \\
\hline $\mathbf{1}$ & Espressivo & 7 & 6 & Cantabile & 34 \\
$\mathbf{2}$ & Robusto & 13 & $\mathbf{7}$ & Tempo I mo & 50 \\
$\mathbf{3}$ & cantando lamentoso & 18 & $\mathbf{8}$ & Marcato & 59 \\
$\mathbf{4}$ & meno mosso & 34 & $\mathbf{9}$ & & 43 \\
III & General character & Allegro non troppo $(-\mathbf{~}=\mathbf{8 8}$ & /I/ & Change frequency & $\mathbf{1 0}$ \\
\hline
\end{tabular}

Table 5. Dynamics in Fantasia rustica.

\begin{tabular}{|c|c|c|c|}
\hline Section & Bar & Changes & $\begin{array}{l}\text { Change } \\
\text { frequency }\end{array}$ \\
\hline I & $1-17$ & $\begin{array}{l}m f \text {, cresc., decresc., mp, cresc., decrecs., decresc., decresc., decresc., } \\
\text { cresc., cresc., cresc., f.cresc., cresc., cresc., cresc }\end{array}$ & 17 \\
\hline II & $18-24$ & mp, decresc., cresc., decresc., & 4 \\
\hline III & $25-48$ & $\begin{array}{l}\text { poco a poco crescendo, cresc., f, cresc., ff, decresc, mp, decresc., cresc., } \\
\text { decresc., cresc., decresc., pp, cresc, decresc, cresc., cresc., decresc }\end{array}$ & 18 \\
\hline IV & $49-63$ & $\begin{array}{l}\text { mp, cresc, cresc., decresc., cresc., cresc., decresc., decresc., f, cresc., } \\
\text { cresc., ff }\end{array}$ & 12 \\
\hline Total & 63 & Dynamic changes & 51 \\
\hline
\end{tabular}

suggestion described by cantando lamentoso. A subjective analogy, based on musical content and comparative purpose, would lead to the classification of this segment as dramaturgy deriving from the mourning songs of the Albanian folklore tradition, particularly the rustic one. This lamentoso and the dynamic frame $p$ increases and develops through crescendos up to $\mathrm{ff}$ in the B-30, reaching the climax of lamenting, calamity. The release of this dramaticity is achieved by the composer through the agogically varied segment meno mosso (B-34) by transforming the flow into cantabile. This relatively long segment (B-34-49) brings a significantly quieter section both dynamically and in terms of melodic and harmonic organization. In this sequence, the dynamics reaches $p p(\mathrm{~B}-42)$ for the first time, wherefore the interpretation, without changing the dynamic frame $p p$, moves lightly from crescendo to decrescendo and up to B-49. The B-50, in addition to the restoration of the first Allegro non troppo tempo, enters with the dynamics taken from the previous segment and by $m p$, with the forward-backward dynamic movement, developing to $f f(B-62)$, which marks the dynamic conclusion of the whole work (See Table 5).

\section{Synthesis of Musical Parameters in the Process of Concretization}

The preceding analysis provided a wide overview of content elements which could serve as a basis for the process of interpretation according to the principles of $\mathrm{H}$. Neuhaus. According to Neuhaus from two approaches for pianistic procession of a certain work: psychological and musical, the latter directs us more to- 
wards a rather real end of interpretation (Neughaus, 2000). Through the synthesis of musical parameters, the interpreting activity approaches a process of unifying the layers which constitute the work, as suggested by the aesthete Hartman (Hartman, 1979).

The title of the work Fantasia rustica defines the general interpretation approach. The pianist must bring a plethora of colours in order to reflect the rustic atmosphere, which rises up to fantasy as a stage of experience. In the first section (B-1-17), the ornamentation and the rhythmic arrangement of the melody (an eighth with two semiquavers) play a dominant role in shaping the artistic imagination. Their intertwining over to the linear plane of the allegro non troppo character, leaving the vertical structures in the second plan, creates the initial movement and dramaturgy. Although there are frequent changes in the metric bar (in 17 bars there are 15 changes), they do not incite any aesthetic function and have no dramatic impact on the flow of the work. They simply serve as the basis for the establishment of freely organized linear structures. From what has been noticed, the interpretation can be performed with a tonal colour of the Impressionist type, foregrounding the espressivo shown in B-7. In B-11, dynamics interferes as a change factor to direct the flow to anf-robusto in B-13. Here starts the cadence segment, which stripes the flow from the melorhythmic movement, based on the movement of the verticals as cadence elements. The section extending from B-18-24, with the melodic-rhythmic content slightly changed to the initial material is dominated by the cantando lamentoso character. This segment also foregrounds the slight rhythmic change of ornaments from the first section, which now appear to be rhythmically modified in demisemiquaver, which implies that the flow is aggravating and interacting with cantando lamentosso. This short segment should be shaped as an intermediate state between Section 1 and the following section from B-25-49. During the process of concretization, this segment should be treated as a dialogue of two contrasting characters, one (B-25-33) dominated by dynamic gradation, culminating to $f f$, and the other (B-34-49) which besides the contrasting dynamics within $p$, is also dominated by the tempo-character as it moves in meno mosso and cantabile. Return on tempo I-mo in B-50 restores many of the predominant parameters of section I: the melo-rhythmic structure, tempo-character, dynamics, etc. This is how the last section functioning as a kind of repetition begins. Thus, it begins the initial optimism that will be developed with a dynamics up to ff and to the conclusion with consonant structures.

In this work, the timbre must be performed taking into account all the musical parameters that build its own structure such as: consonant structures, melody, dynamics, character and thematics, tempo, agogics, ornaments etc. The timbre consists of a colour hierarchy in the vertical, which should play a manifold aesthetic role in interpretation, such as: identifying each of the tones of the vertical, their uninterrupted consonance, detailing all changes occurring in the melodic line, evidencing the basic melodic material, achieving the intended ex- 
pressiveness, realizing the emotional character of the various segments. Although the composer has not used signs of pedaling, the work offers great opportunities for applying different types of pedal points as an additional tool for interpretive creativity.

Fantasia rustica has a relatively rich facture and contains: polyphonic, choral-chord, homophonic segments. Since both hands appear balanced both in terms of technical requirements and of the leading role of the main melodic material, the categorization of the work "for the left hand" (according to the note in the title Due pezzi per pianoforte-a mano sinistra) seems unnecessary. Even here, as in Echi delle Montagne Maledette, during the practical performance of the work, at certain moments there are reasons and opportunities for reorganizing the roles and tasks for the hands.

\section{Conclusion}

Fantasia rustica, as an initial composing endeavour of Ballata, is built upon a melodic base in the spirit of Albanian folk music, which is then elaborated through a complete contemporary, namely postmodernist treatment. Although ornamentism in Ballata's creations is a rare means of expression, its presence in this piece is organized in a way to determine and describe the semantic object included in the title of the piece. The overall flow, structured into four sections which retake, process, and variate elements from the first section, is during the whole flow elaborated through vertical dissonant structures. As an atonal piece, the organization of atonal structures is based on the logic of overlapping dissonant intervals. Special characteristics noticeable in this piece are temporary consonant strikes, which create an illusion of tonalism, moments these, which together with ornaments ascribe lyrism elements to the piece. The rhythmical organization of Fantasia rustica, respectively that of metre which often differs from five to two fourths while the metrical unit remains unaltered, is characteristic for almost all Ballata's works. Thus, one notices that such a metrical frame is a product of a subjective and instictive thinkingframe rather than a deliberate means for creating a certain aesthetic effect.

\section{Conflicts of Interest}

The author declares no conflicts of interest regarding the publication of this paper.

\section{References}

Ballata, Z. (1970). Dve skladbi za klavir. Ljubljana: ED. DSS.

Berisha, E. (1997). Zhvillimi i stileve në veprat e kompozitorëve shqiptarë të Kosovës. Prishtina: EBTMM Kosovo.

Dušan, S. \& Vlastimir, P. (1986). Nauka o muzičkim oblicima. Belgrade: University of Arts-Belgrade.

Foght, I. (1980). Savremena estetika muzike. Belgrade: NOLIT.

Hartman, N. (1979). Estetika. Belgrade: BIGZ. 
Križnar, F. (2004). Mjetet dhe gjuha shprehëse kompozicionale-teknike në opusin e kompozitorit Zeqirja Ballata-(Studime, pp. 155-165). Prishtina: AShAK.

Mančev, T. (2001). Dviženjeto-Suštinski element kaj simfoniskoto tvoreštvo. Skopje: SOKOM.

Michel, D. (1983). The Language of Modern Music. Belgrade: Nolit.

Neughaus, H. (2000). O umjetnosti sviranja klavira. Zagreb: Jakša Zlatar. 